\title{
Upaya Peningkatan Kinerja Guru Melalui Teknik Lesson Study Secara Kolaboratif dan Rutin Di SDN Inpres 1 Wora Semester Genap Tahun Pelajaran 2018/2019
}

\author{
Fatimah H. Yasin \\ SDN 1 Wora \\ Email:fatimah_yasin65@gmail.com
}

\begin{abstract}
Lesson study merupakan kerja kolektif sekelompok guru (atau anggota MGMP), bisa dengan mahasiswa dan dosen. Pembuatan rencana pembelajaran (planning) dapat dikerjakan secara bersama-sama, diimplementasikan dengan menunjuk salah satu anggota sebagai guru model, guru lain dan pakar bertindak sebagai observer, kemudian dari hasil observasi tersebut dianalisis (melalui tahapan reflecting) secara bersama-sama.. Penelitianini bertujuan untuk Upaya Peningkatan Kinerja Guru Melalui Teknik Lesson Study Secara Kolaboratif dan Rutin Di SDN Inpres 1 Wora Tahun Pelajaran 2018/2019. Jenis ini adalah Penelitian Tindakan Sekolah (PTS), yang dirancang dalam dua siklus, tiap siklus terdiri dari empat tahapan, yaitu: perencanaan, pelaksanaan, pengamatan, dan refleksi. Subyek dalam penelitian ini adalah guru SDN 1 Wora sebanyak 20 orang. Instrumen yang digunakan dalam penelitian ini adalah lembara penilaian RPP dan lembar observasi. Berdasarkan analisis data, yang telah dilakukan maka dapat disimpulkan ada Peningkatan Kinerja Guru Melalui Teknik Lesson Study Secara Kolaboratif dan Rutin Di SDN Inpres 1 Wora Semester Genap Tahun Pelajaran 2018/2019, pada Siklus nilai rata-ratanya sebesar 25,6, meningkat menjadi 34,15 pada Siklus ke II
\end{abstract}

Keywords: Kinerja guru, Lesson study, Kolaboratif

\section{PENDAHULUAN}

Guru sebagai pendidik profesional dengan tugas utama mendidik, mengajar, membimbing, mengarahkan, melatih, menilai, dan mengevaluasi peserta didik membutuhkan peningkatan profesional secara terus menerus. Melalui Penelitian Tindakan Kelas (PTK), seorang pendidik memperoleh pemahaman tentang apa yang harus dilakukan, merefleksi diri untuk memahami dan menghayati nilai pendidikan dan pembelajarannya sendiri, dapat bekerja secara kontekstual, dan mengerti sejarah tentang pendidikan (Kemmis dan Mc Taggart dalam Aswandi, 2006). Penelitian tindakan kelas dapat dijadikan sarana bagi pendidik dalam meningkatkan kualitas pembelajaran secara efektif (Sukanti, 2008). PTK memiliki potensi yang sangat besar untuk meningkatkan pembelajaran apabila diimplementasikan dengan baik dan benar. Pendidik dapat meningkatkan pembelajaran

dengan cara melakukan kolaborasi dengan pendidik lain untuk merancang, mengamati, dan melakukan refleksi terhadap pembelajaran yang dilakukan (Syamsuri, 2008).

Sehubungan dengan strategi peningkatan kualitas pembelajaran tersebut, pendidik juga dapat meningkatkan pembelajaran melalui kegiatan lesson study. Mulyana (2006) memberikan rumusan tentang lesson study sebagai salah satu model pembinaan profesi pendidik melalui pengkajian pembelajaran secara kolaboratif dan berkelanjutan berlandaskan pada prinsipprinsip kolegalitas dan mutual learning untuk membangun komunitas belajar.

Dari uraian di atas, maka ilakukan upaya terobosan untuk menyikapi sekaligus memperbaiki pola-pola pemikiran yang salah dengan memberikan pengarahan/ pembinaan guru berbasis sekolah yang dinamakan dengan (Lesson Study) secara kolaboratif dan berkelanjutan berlandaskan prinsip-prinsip kolegalitas dan mutual learning untuk membangun komunitas belajar, untuk membekali guru dalam melaksanakan tugasnya sebagai agen pembelajaran. Kata kuncinya adalah "rutinitas" penulis 
mempunyai keyakinan bahwa dengan pengarahan secara rutin, terprogram dengan baik dan kontrol terhadap persiapan guru sebelum melaksanakan tugas mengajar di kelas maka akan terbentuk tenaga pendidik yang produktif/ profesional dan mampu meningkatkan mutu pembelajaran. Memang, dalam awal-awal pelaksanaan program ini ada beberapa diantara guru yang menunjukkan sikap acuh tak acuh, tetapi dengan kesabaran dan ketekunan akhirnya guru tersebut sangat antusias setelah merasakan dampak dan manfaat yang dapat dipetik dari pelaksanaan program tersebut.

Lesson study mulai dikenal di Jepang pada tahun 1900-an, sebuah metode analisis kasus pada proses pembelajaran, ditujukan untuk membantu pengembangan profesional para guru dan membuka kesempatan bagi mereka untuk saling belajar berdasarkan praktik-praktik nyata di tingkat kelas (Rusman, 2010:287). Sukirman (2006:4) mengatakan bahwa: Lesson study merupakan kerja kolektif sekelompok guru (atau anggota MGMP), bisa dengan mahasiswa dan dosen. Pembuatan rencana pembelajaran (planning) dapat dikerjakan secara bersama-sama, diimplementasikan dengan menunjuk salah satu anggota sebagai guru model, guru lain dan pakar bertindak sebagai observer, kemudian dari hasil observasi tersebut dianalisis (melalui tahapan reflecting) secara bersama-sama.

Berdasarkan latar belakang tersebut dipandang perlu untuk melakukan penelitian dengan judul: "Upaya Peningkatan Kinerja Guru Melalui Teknik Lesson Study Secara Kolaboratif dan Rutin Di SDN Inpres 1 Wora Semester Genap Tahun Pelajaran 2018/2019.

\section{METODE \\ Jenis Penelitian}

Penelitian ini adalah Penelitian Tindakan Sekolah (PTS). Kegiatan penelitian tindakan sekolah ini, dilaksanakan dalam 2 silus, tiap siklus terdiri dari empat tahapan, yaitu: perencanaan, pelaksanaan, pengamatan, dan refleksi (Azmin, 2019). Tahapan kegiatan dapat disajikan pada gambar 1 berikut:

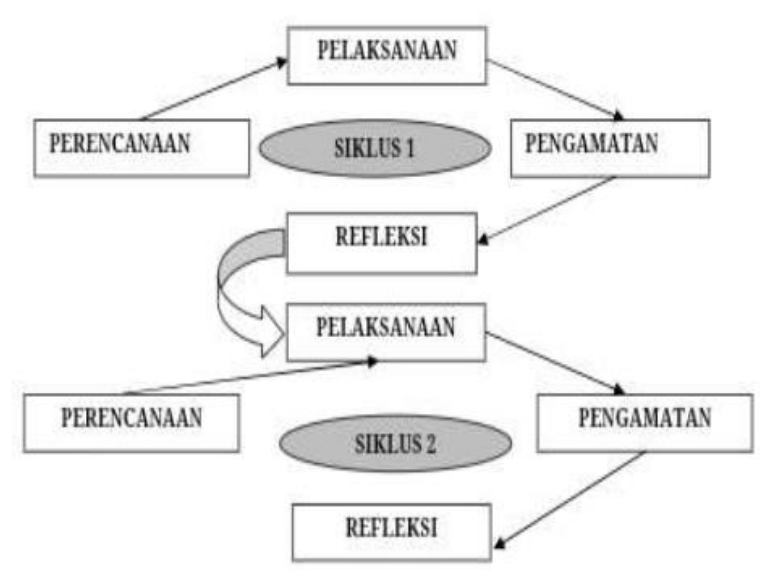

Gambar 1. Langkah-langkah PTS

\section{Waktu dan Tempat Penelitian}

Penelitian ini dilaksanakan di SDN Inpres 1 Wora Semester Genap Tahun Pelajaran 2018/2019.

\section{Subyek Penelitian}

Subyek dalam penelitian ini adalah guru-guru SDN Inpres 1 Wora sebanyak 20 orang.

\section{Rencana Tindakan}

\section{Perencanaan}

Perencanaan Tindakan Sekolah dilakukan dengan penilaian terlebih dahulu terhadap kebutuhan-kebutuhan guru yang diperoleh dari informasi hasil pembicaraan dengan guru. Diperoleh kesimpulan bahwa guru memiliki keterbatasan dalam menyusun RPP. Permasalahan ini diangkat menjadi isu pembinaan dengan memberikan penyuluhan tentang penyusunan RPP. Sebagai langkah pertama adalah melakukan penilaian terhadap RPP yang disusun oleh guru dengan menggunakan instrumen penilaian RPP. Teknik dan alat pengumpul data adalah menggunakan teknik observasi atau pengamatan terhadap dokumentasi perangkat pembelajaran guru (RPP) dan eksen pembelajarannya di kelas

\section{Pelaksanaan Tindakan}

Setelah dilakukan penilaian terhadap RPP, dilakukan penyuluhan penyusunan RPP sesuai pedoman

\section{Pengamatan.}

RPP yang sudah disusun dilaksanakan dikelas dengan menggunakan instrumen sebagai berikut: 


\section{Refleksi.}

Tindakan tersebut diimplementasikan dalam tiga siklus tindakan dan setiap siklus diakhiri dengan refleksi. Siklus pertama penilaian RPP menghasilkan penilaian perlunya diberi penyuluhan penyusunan RPP. Siklus kedua yaitu melakukan pembinaan melalui tekhnik Lesson Study dan siklus ketiga menghasilkan pembicaraan lebih lanjut tentang supervisi akademik (pembuatan RPP).

\section{HASIL DAN PEMBAHASAN Hasil Penelitian}

Pelaksanaan PTS yang direncanakan oleh penulis dalam bentuk pelaksanaan Penelitian Tindakan Kelas dengan judul "Upaya Peningkatan Kinerja Guru Melalui Tekhnik Lesson Study Secara Kolaboratif dan Rutin Di SDN Inpres 1 Wora " berjalan sesuai dengan perencanaan Penelitian Tindakan Sekolah (PTS).

Hasil penelitian yang direfleksi dari permasalahan yang menjadi fokus penelitian menunjukan hasil yang membawa pengaruh positif pada guru. Terlihat dari hasil penelitian. Hasil penilaian dapat terlihat pada tabel di bawah ini:

Tabel 1. Rekapitulasi Hasil Penilaian

\begin{tabular}{|c|c|c|c|}
\hline \multirow{2}{*}{ No } & \multirow{2}{*}{ Nama Guru } & \multicolumn{2}{|c|}{$\begin{array}{c}\text { Nilai Hasil } \\
\text { Evaluasi }\end{array}$} \\
\hline & & $\begin{array}{c}\text { Siklus } \\
\text { I }\end{array}$ & $\begin{array}{c}\text { Siklus } \\
\text { II }\end{array}$ \\
\hline 1 & Ningyu,S.Pd.I & 25 & 35 \\
\hline 2 & Hj. Siti Nurhayati & 26 & 32 \\
\hline 3 & Aprin,S.Pd & 28 & 34 \\
\hline 4 & Yati Indriani,S.Pd.I & 26 & 33 \\
\hline 5 & Yati,S.Pd & 25 & 34 \\
\hline 6 & Wahyu Ilahi,S.Pd & 24 & 35 \\
\hline 7 & Siti Hajar,S.Pd.I & 25 & 35 \\
\hline 8 & $\begin{array}{l}\text { Emi } \\
\text { Widiastuti,S.Pd }\end{array}$ & 26 & 34 \\
\hline 9 & Hayatulnufus,S.Pd & 25 & 32 \\
\hline 10 & Adadiyah,S.Pd & 27 & 35 \\
\hline 11 & Arifman,S.Pd.I & 27 & 35 \\
\hline 12 & Zakariah,S.Pd.I & 28 & 33 \\
\hline 13 & Marfah,S.Pd & 27 & 35 \\
\hline 14 & $\begin{array}{l}\text { Egi } \\
\text { Setiawan,S.Pd.SD }\end{array}$ & 25 & 34 \\
\hline 15 & Intan,S.Pd.I & 24 & 35 \\
\hline 16 & Nurhayati,S.Pd.SD & 25 & 35 \\
\hline
\end{tabular}

Jurnal Pendidikan Mandala

\begin{tabular}{|c|l|c|c|}
\hline 17 & $\begin{array}{l}\text { Mustiawan } \\
\text { Aryanto,S.Pd }\end{array}$ & 26 & 34 \\
\hline 18 & Aswadin,A.Ma.Pd & 23 & 35 \\
\hline 19 & Kiflin,A.Ma & 26 & 34 \\
\hline 20 & $\begin{array}{l}\text { Leti } \\
\text { Kurniawansyari,S.I } \\
\text { P }\end{array}$ & 24 & 34 \\
\hline \multicolumn{2}{|c|}{ Jumlah } & 512 & 683 \\
\hline \multicolumn{2}{|l|}{ Rata-Rata } & 25,6 & 34,15 \\
\hline
\end{tabular}

Penguasaan guru dalam melakukan pembelajaran mengalami peningkatan dari siklus pertama ke siklus kedua setelah diberikan teknik Lesson Study Secara Kolaboratif dan Rutin secara rutin mengenai penyusunan RPP yang benar, materi pelajaran yang akan disampaikan dari siklus ke siklus. Siklus ke I mencapai rata-rata nilai 25,6, Siklus ke II mencapai 34,15, Dari 20 guru SDN Inpres 1 Wora. Rata-rata peningkatan hasil disajikan dalam diagram berikut ini:

\section{Hasil Penilaian}

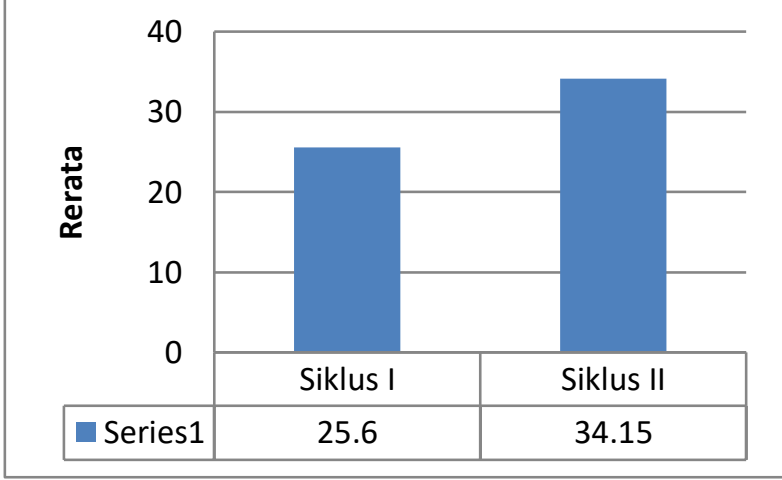

Berdasarkan temuan-temuan yang didapat selama mengadakan penelitian terhadap pelaksanaan tugas sehari-hari sebagai kepala sekolah dan penerapan metode Lesson Study secara rutin sebelum guru melakukan tugas mengajar menunjukkan adanya peningkatan produktifitas, profesional dan mutu pembelajaran di kelas.

\section{PEMBAHASAN}

Kondisi awal sebelum diterapkan metode Lesson Study secara rutin sebelum guru melakukan tugas mengajar menunjukkan:

1. Kurangnya kesadaran dan tanggung jawab guru akan tugas pokok dan fungsi yang dibebankan oleh pemerintah. 
2. Kurangnya perencanaan yang matang dalam melaksanakan tugas dan belum siapnya guru untuk mengadakan perubahan kearah yang lebih maju sesuai dengan perkembangan dunia pendidikan.

3. Kurangnya pemahaman guru akan tugasnya sebagai agen pembelajaran.

4. Belum terbentuknya disiplin sekolah dan iklim budaya kerja sekolah yang mengacu pada peningkatan mutu pembelajaran.

Pemahaman guru terhadap tugas sebelum diterapkannya pendekatan tersebut adalah dalam melaksanakan tugasnya hanya mengandalkan persiapan seadanya bahkan kadang sama sekali tidak ada persiapan. Hal ini terjadi karena fungsi kontrol sebagai salah satu tugas kepala sekolah tidak berjalan sebagaimana mestinya. Disamping itu seolaholah guru hanya sekedar melaksanakan tugas tanpa ada perancanaan yang matang dan tidak berpikir bagaimana hasil akhir setelah melaksanakan tugas mengajar. Dapat dibayangkan jika seorang kepala sekolah tidak mempunyai kemampuan untuk mengatur, memimpin, mengelola atau mengadministrasikan sumber daya meliputi perencanaan, pelaksanaan, pengawasan, dan pembinaan terhadap guru-guru sebagai bawahannya.

Teknik Lesson Study dikemas agar menarik, memukau dan apa yang kepala sekolah sampaikan langsung masuk dan dapat diaplikasikan dalam kegiatan pembelajaran oleh guru-guru.

Pertama kali yang harus disadari adalah apa yang akan kita sampaikan. Kepala sekolah harus memahami visi sekolah. Visi sekolah akan menurunkan Misi yang sekolah buat dalam waktu yang pendek. Misi yang sekolah buat inilah yang akan menurunkan culture kerja. Culture kerja inilah yang kemudian akan memunculkan Motivasi kerja. Jadi dengan memahami Visi, kepala sekolah akan dapat menciptakan budaya kerja dalam tim sekolah dan sekaligus memunculkan motivasi personil.

Yang kedua, yang harus kepala sekolah sadari bahwa pada saat teknik Lesson Study dimulai, kepala sekolah harus menyadari secara sepenuhnya bahwa teknik ini adalah teknik yang berkesinambungan, yang akan membutuhkan waktu untuk bisa beradaptasi dengan teknik baru, maka diperlukan keuletan dan kesabaran dalam mengolah manajemen di sekolah.

Strategi melaksanakan lesson study berdasarkan hasil penelitian penulis:

\section{Perencanaan (Plan)}

a) Identifikasi Masalah Pembelajaran

1. Materi Ajar
a. kedalaman materi
b. kesesuaian dengan tuntutan
kurikulum
c. tingkat kesulitan

2. Strategi Pembelajaran

a. Pendahuluan

Memotivai siswa belajar

b. Kegiatan inti

1. Aktivitas belajar yang diharapkan

2. Rancangan interaksi siswa dengan bahan ajar

3. Rancangan interaksi siswa dengan siswa

4. Rancangan interaksi siswa dengan guru

3. Penutup

Aktivitas siswa yang diharapkan untuk menyimpulkan pelajaran

2. Mempersiapkan Perangkat

Pembelajaran

1. Silabus

2. Rencana

Pelaksanaan Pembelajaran

3. Lembar Kegiatan Siswa

4. Alat tes

A. Menentukan Observer

1. Kepala Sekolah

2. Guru

3. Pengawas Sekolah

B. Menentukan Guru Model (pelaksana pembelajaran di kelas)

\section{Pelaksanaan (Do)}

b) Pertemuan singkat (briefing) dipimpin fasilitator (kepala sekolah).

c) Guru model mengemukakan rencana singkat (rencana pembelajaran, tujuan, 
kedudukan materi ajar dalam kurikulum, perkiraan kemungkinan respon siswa).

d) Kepala sekolah mengingatkan observer untuk tidak mengintervensi proses belajar mengajar.

e) Observer dipersilahkan memilih tempat strategis sesuai rencana pengamatan.

f) Guru model melaksanakan proses belajar mengajar.

\section{Observasi}

Observer membuat catatan tentang:

a) Komentar siswa dalam diskusi.

b) Kerja sama siswa.

c) Aktivitas belajar.

d) Strategi penyelesaian masalah.

Pedoman observer:

a) Kejelasan tujuan pembelajaran.

b) Aktivitas mengarah ke pencapaian tujuan.

c) Langkah-langkah pembelajaran berkaitan mendukung pemahaman siswa.

d) Media pembelajaran mendukung pencapaian tujuan.

e) Diskusi kelas membantu pemahaman konsep.

f) Materi ajar sesuai tingkat kemampuan siswa.

g) Penggunaan pengetahuan awal untuk mendukung pemahaman konsep.

h) Pertanyaan guru mendorong dan memfasilitasi cara berpikir siswa.

i) Pemberian penghargaan gagasan siswa.

j) Kesimpulan didasarkan pendapat siswa.

k) Kesimpulan sesuai tujuan.

1) Pemberian penguatan.

\section{Refleksi (See)}

a) Menentukan fasilitator.

b) Fasilitator mengenalkan observer dengan spesifikasi bidang ilmu.

c) Fasilitator menyampaikan agenda refleksi.

d) Fasilitator menyampaikan aturan main.

1) Berbicara dengan tertib (jadi pendengar yang baik)

2) Berbicara sopan tidak untuk mengadili guru model

3) Setiap peserta diberi kesempatan berbicara
4) Berbicara berdasarkan temuan pengamatan

5) Masukan difokuskan pada "bagaimana siswa belajar"

e) Guru model menyampaikan:

1) Kejadian yang sesuai dan yang tidak sesuai dengan harapan.

2) Sesuatu yang berubah dari rencana.

f) Team pengembang memberi komentar.

g) Fasilitator memberi kesempatan observer berkomentar

h) Fasilitator mempersilahkan tenaga ahli merangkum diskusi.

Fasilitator mengucapkan terimakasih dan mengumumkan kegiatan lesson study berikutnya.

\section{KESIMPULAN}

Berdasarkan pembahasan hasil penelitian yang telah dilakukan dalam dapat disimpulkan bahwa ada Peningkatan Kinerja Guru Melalui Teknik Lesson Study Secara Kolaboratif dan Rutin Di SDN Inpres 1 Wora Semester Genap Tahun Pelajaran 2018/2019, pada Siklus nilai rata-ratanya sebesar 25,6, meningkat menjadi 34,15 pada Siklus ke II.

\section{DAFTAR PUSTAKA}

Arikunto, S. 2010. Prosedur Penelitian Suatu Pendekatan Praktek. Jakarta:Rineka Cipta.

Aswandi. 2006. Guru sebagai Peneliti. (Online). http://www.pontianakpost.com).

Azmin, N., \& Nasir, M. (2019). PENERAPAN MODEL PEMBELAJARAN 5E UNTUK MENINGKATKAN

KETERAMPILAN PROSES SAINS DAN SIKAP ILMIAH SISWA KELAS VIII SMP NEGRI 6 KOTA BIMA. ORYZA Jurnal Pendidikan Biologi, 8(2), 40-46.

Mulyana, S. 2006. Pelatihan Lesson Study untuk Guru-guru Berprestasi Tingkat Nasional. Laporan Kegiatan Pelatihan Tahun 2006.

Syamsuri, I dan Ibrohim. 2007. Lesson Study (Studi Pembelajaran). Malang: UM Press. 
Yayat Hidayat Amir dan Anwar, Idochi. 2000. Administrasi Pendidikan:

Teori,

Konsep \& Issu, Bandung : Program

Pasca Sarjana UPI Bandung. 